\title{
Violência obstétrica: ativismo nas redes sociais
}

\author{
Lia Hecker Luz, Vânia de Vasconcelos Gico
}

\author{
Universidade Federal do Rio Grande do Norte - UFRN, Natal, RN, Brasil.
}

\begin{abstract}
Resumo: Discute-se o parto normal na contemporaneidade e apresentam-se os três modelos de assistência obstétrica, a partir de categorização proposta pela antropóloga norte-americana Davis-Floyd, apontando-se as consequências do modelo tecnocrático que se tornou hegemônico nas sociedades contemporâneas e que naturalizou a violência obstétrica. Contextualiza-se a problemática à realidade brasileira, evidenciando-se, a partir da análise do blog Cientista que virou mãe, o movimento que se articula entre mulheres brasileiras nas redes sociais com o intuito de defender e dar visibilidade a iniciativas de parto natural e humanizado, atuando contra a violência obstétrica. Conclui-se que as ferramentas da internet têm permitido uma mobilização inédita em prol do respeito aos direitos reprodutivos das mulheres no Brasil, tornando tais canais em vias alternativas de comunicação e informação para alcançar formas mais democráticas de organização social. Além de desnaturalizar a violência obstétrica, as blogueiras também lançam ações que buscam pavimentar o caminho para a assistência humanizada e para as iniciativas de parto domiciliar planejado.
\end{abstract}

Palavras-chave: Rede Social, Parto Humanizado, Violência Obstétrica.

\section{Obstetrical violence: activism on social networking}

\begin{abstract}
Normal birth in contemporaneity is discussed and the three models of birth care are presented, accordingly to categorization proposed by the north-American anthropologist Davis-Floyd, pointing out the consequences of the technocratic model, which has become hegemonic in contemporary societies, naturalizing obstetrical violence. The problematic is contextualized to Brazilian reality, with the analyses of the blog Cientista que virou mãe making it evident that Brazilian women on social media are articulating themselves in order to defend and give visibility to initiatives of natural and humanized birth, acting against obstetrical violence. It is concluded that Internet tools have allowed a pioneer mobilization in respecting women's reproductive rights in Brazil, turning blogs into a potential hegemonic alternative way to reach more democratic forms of social organization. In addition to denaturalize the obstetrical violence, the bloggers also act aiming to pave the way for the humanistic approach and to motivate planned home birth initiatives.
\end{abstract}

Keywords: Social Networking, Humanizing Delivery, Obstetrical Violence.

\section{0 parto na contemporaneidade}

Falar sobre parto normal na contemporaneidade não é uma tarefa consensual. Pelo contrário, significa adentrar num universo conceitual que, influenciado por questôes sociais, culturais, políticas e econômicas, é pautado por ambiguidades e divergências, e pela falta de clareza em distinguir o que é normal e o que é comum, na assistência obstétrica. Nas últimas décadas, convencionou-se empregar o termo para descrever realidades das mais díspares, as quais muitas vezes estáo situadas em extremos virtuais das possibilidades do parto vaginal.

$\mathrm{O}$ apagamento de fronteiras faz com que, na atualidade, possam estar, dentro do mesmo espectro de "normalidade" no parto, abordagens muito distintas. De um lado, podemos ter o parto domiciliar acompanhado por parteira e com o

Autor para correspondência: Lia Hecker Luz, Universidade Federal do Rio Grande do Norte, Campus Universitário Lagoa Nova, CEP 59078-970, Natal, RN, Brasil, e-mail: liahluz@gmail.com

Recebido em Nov. 10, 2014; $1^{\text {a }}$ Revisão em Maio 23, 2015; 2a Revisão em Jun. 9, 2015; Aceito em Jun. 12, 2015. 
mínimo de intervençóes possíveis, uma realidade que representa mais de $30 \%$ dos nascimentos na Holanda (DE VRIES et al., 2009); e, de outro, o modelo hospitalar privativo brasileiro, com controle da dor por analgesia peridural, utilização de ocitocina sintética e realização da episiotomia - práticas frequentes usadas de modo inadequado e náo recomendadas pela Organização Mundial da Saúde (ORGANIZAÇÃO..., 1996).

Até o início do século 20, essas ambiguidades tendiam a ser menos abrangentes, uma vez que as mulheres comumente tinham seus partos em casa, assistidas por parteiras, sendo rara a hospitalizaçáo na maioria dos países. Pouco seguras, as cesarianas eram procedimentos de exceção, sendo realizadas apenas quando as tentativas do nascimento por via vaginal haviam sido esgotadas. Todavia, com o crescente interesse da obstetrícia médica pelos partos e com a (pseudo) segurança dessa área em realizar diversos procedimentos, acompanhada da visão mercadológica do processo saúde-doença, passou a haver progressivo aumento dos partos hospitalares e cirúrgicos em todo o mundo.

A mudança do parto em domicílio para o hospital eliminou grande parte do calor humano e abriu caminho para uma série de intervençōes (RATTNER; AMORIM; KATZ, 2013), construindo uma concepção atual de parto normal distante da defendida na literatura da Medicina baseada em evidências (ODENT, 2002, 2005a; ORGANIZAÇÃO..., 1996; BRASIL, 2011). Mesmo na academia, muito da pesquisa médica sobre parto normal é, em realidade, sobre partos hospitalares marcados por inúmeras intervençôes, os quais são considerados normais pelo simples fato de as pesquisas serem conduzidas em hospitais, onde o parto poderia teoricamente ser chamado normal, porque é comum dar à luz em hospitais e é comum o hospital intervir (DAVIS-FLOYD et al., 2009).

Segundo Dutra e Meyer (2007), o parto normal passou a ser entendido, na contemporaneidade, como sinônimo de um parto por via vaginal com intervençóes medicamentosas e técnicas associadas a regulamento institucional. "Nesse sentido, normal diz respeito à norma, regulando e prescrevendo os modos como elas (as mulheres) devem ou não se portar nos centros obstétricos [...]" (DUTRA; MEYER, 2007, p. 219). De acordo com essa compreensão, anormal poderia ser, portanto, a brasileira de classe média que, no setor de saúde suplementar, reivindica parir sem anestesia peridural e sem passar por uma episiotomia, práticas rotineiras em hospitais particulares do país (JONES, 2009; RATTNER; AMORIM; KATZ, 2013).
Na miríade de sentidos que o termo carrega, ainda há de se considerar que aquilo que é normalidade para um grupo pode configurar-se como exceção para outros. Se, por exemplo, com a institucionalização disseminada do parto desde a década de 1930, a possibilidade de parto domiciliar desapareceu em muitos países centrais e semiperiféricos, mesmo onde ele não foi proibido, em muitos países periféricos "[...] grandes distâncias entre mulheres e as instituiçôes de saúde restringem as opçôes e fazem com que o parto domiciliar seja a única escolha [...]" (ORGANIZAÇÃO..., 1996, p. 22).

Já nos países em que o parto hospitalar transformou-se em norma, como o Brasil, o parto domiciliar planejado passou a ser buscado como uma das opçóes válidas dentro do direito da mulher sobre o seu próprio parto. Na saúde complementar brasileira, cujo modelo prioritário de assistência obstétrica é o intervencionista, não seria arriscado dizer, portanto, que o parto domiciliar planejado pode ser visto como uma alternativa buscada por mulheres insatisfeitas com o modelo de institucionalizaçáo do corpo feminino e com condiçôes econômicas para custear uma assistência particular. Porém, em regiôes do mundo em que menos de $20 \%$ das mulheres têm acesso a qualquer tipo de maternidade formal (ORGANIZAÇÁO..., 1996), o parto domiciliar é virtualmente inevitável.

Tem-se, assim, que falar de parto normal na contemporaneidade pode significar diferentes realidades e entendimentos. $\mathrm{O}$ conceito, por exemplo, pode abarcar dentro do mesmo espectro de "normalidade" modelos de assistência distintos, mas pode, também, ser empregado com a finalidade de descrever as rotinas de um parto vaginal hospitalar e com intervençôes, ou seja, o modelo adotado na sociedade ocidental contemporânea.

Para a Organização Mundial de Saúde, o parto normal se relaciona a dois fatos - o risco da gestação e a evolução do trabalho de parto -, sendo definido como:

[...] de início espontâneo, baixo risco no início do trabalho de parto, permanecendo assim durante todo o processo, até o nascimento. $\mathrm{O}$ bebê nasce espontaneamente, em posição cefálica de vértice, entre 37 e 42 semanas completas de gestaçấo. Após o nascimento, mãe e filho em boas condições (ORGANIZAÇÃO..., 1996, p. 9).

Em sintonia com a visão internacional, o Ministério da Saúde (BRASIL, 2013) adota definição bastante similar, sendo mais específico em relação ao entendimento de nascimento de forma espontânea, 
afirmando ser o parto normal aquele com trabalho de parto de início espontâneo, sem indução, sem aceleraçáo, sem utilização de intervençóes, como fórceps ou cesariana, sem uso de anestesia geral, raquiana ou peridural, durante o trabalho de parto e o parto.

Se essas definições fossem levadas em consideração, poder-se-ia perguntar quantos partos normais no Brasil e no mundo poderiam ser, de fato, assim chamados? A resposta a essa indagação retorna ao ponto já sinalizado: existe, na atualidade, uma distância muito grande entre o conceito de parto normal (ORGANIZAÇÃO..., 1996) e o que se convencionou chamar, na prática, de parto normal.

Seja como for, o objetivo da assistência é ter uma mãe e uma criança saudáveis, com o menor nível possível de intervenção compatível com a segurança. Portanto, "[...] no parto normal, deve existir uma razão válida para interferir no processo natural [...]" (ORGANIZAÇÃO..., 1996, p. 10). Novamente, questiona-se: Que razóes são essas, na atualidade, que vêm justificando a escalada do modelo tecnocrático de assistência obstétrica e a naturalização da violência obstétrica?

Historicamente, o parto era assistido apenas por mulheres, como curandeiras, parteiras ou comadres, que conheciam as manobras para facilitar o parto, a gravidez e o puerpério, por experiência própria, e eram encarregadas de confortar a parturiente com alimentos, bebidas e palavras agradáveis. $\mathrm{O}$ atendimento ao nascimento era considerado atividade desvalorizada e, portanto, poderia ser deixado aos cuidados femininos, pois não estava à altura do cirurgião. Além disso, os médicos eram raros e pouco familiarizados em assistir parto e nascimento (ARRUDA, 1989; NAGAHAMA; SANTIAGO, 2005).

Contudo, na década de 1917, a partir da utilização do fórceps obstétrico, a profissão de parteira sofreu declínio. Sem condiçóes econômicas de adquirir o equipamento e vistas como intelectualmente inferiores aos homens e incapazes de adquirir novas técnicas, as parteiras passaram a rejeitar o fórceps. $\mathrm{O}$ uso do equipamento permitiu, assim, a intervenção masculina e a substituição do paradigma não intervencionista pela ideia do parto como um ato controlado pelo homem, instaurando o conceito de que parir era perigoso, sendo, por isso, imprescindível a presença de um médico.

Com o advento do capitalismo industrial, a prática da assistência ao parto se consolidou como exercício monopolizado dos médicos, sendo assim legitimado e reconhecido. A apropriação do saber médico e as práticas médicas constituíram fatores determinantes para a institucionalização do parto e a transformação da mulher em propriedade institucional no processo do parto e do nascimento.

As grávidas internadas passaram a ser vistas como pacientes e submetidas a toda uma série de procedimentos e práticas, muitas das quais sem fundamentação científica. Até hoje, as gestantes são continuamente submetidas a vários procedimentos dolorosos e, muitas vezes, desnecessários, incluindo toques frequentes, ruptura artificial da bolsa das águas, infusão rotineira de ocitocina, entre outros, além de muitas vezes serem vítimas de maus tratos verbais, quando não de agressão física (RATTNER; AMORIM; KATZ, 2013).

Ao redor do mundo, porém, há exemplos de sociedades que proporcionam às mulheres escolha verdadeira, em que seus desejos e a fisiologia do parto e do nascimento são honrados, respeitados e confiados. São abordagens baseadas em evidências e que refletem uma constelação de saberes e práticas, estando aquém da tradição médica e dos interesses de mercado.

\section{Abordagens de assistência obstétrica}

A antropóloga norte-americana Davis-Floyd (2001) categoriza os paradigmas de cuidados em saúde que influenciam a assistência aos nascimentos, na contemporaneidade, em três modelos: tecnocrático,

humanista e holístico. Segundo a autora, estes se diferem fundamentalmente entre si pela definição que adotam de corpo e como enxergam a relação deste com a mente. As demais distinçóes decorrem, em boa parte, desse posicionamento.

Paradigma hegemônico na Biomedicina, o modelo tecnocrático de nascimento foi esculpido para atender, preferencialmente, à conveniência dos profissionais de saúde, sendo caracterizado pela institucionalização do parto, pela utilizaçáo acrítica de novas tecnologias e pela incorporação de grande número de intervençôes, muitas das quais desnecessárias, conforme já delineado.

É o sistema de assistência ao parto que reflete os principais valores das sociedades ocidentais contemporâneas, as quais, regidas pelo sistema econômico neoliberal, visam, entre outros aspectos, ao lucro econômico, e estimulam o consumo, a racionalidade científica e a adoção de tecnologia de ponta (DAVIS-FLOYD, 1992, 2001).

O louvor à tecnologia, fundamentado também no comprometimento da Biomedicina com os interesses 
da indústria farmacêutica e de equipamentos médicos (DAVIS-FLOYD, 2001), ajuda a explicar por que a maioria dos procedimentos de rotina em obstetrícia continua a ser usada até hoje, mesmo sem respaldo científico.

Internacionalmente, esse modelo de assistência obstétrica vem sendo tema de discussão e debate, especialmente por parte daqueles que desejam humanizar a Biomedicina. O chamado modelo humanista parte da premissa de que corpo e mente estáo conectados, devotando suprema importância para a influência de estados mentais e emocionais do corpo. Na assistência obstétrica, a essência dessa abordagem, que supervaloriza as necessidades individuais em detrimento das institucionais, é o diálogo e o afeto entre grávida e cuidador.

Idealisticamente e em contraposição ao paradigma tecnocrático, a assistência humanista deve ser baseada em evidências que refletem a ciência e não na tradição médica. Os médicos humanistas devem recriar um local na Medicina para valores humanos de parceria, vínculo e afeto.

Tal modelo humanista continua sendo adotado em muitos países europeus, como Holanda, Suécia, Alemanha, Inglaterra, França e, também, no Japão (HOGA, 2005). Na Inglaterra, país que pauta o funcionamento de seu sistema de saúde em diretrizes fundamentadas em evidências científicas, aumentar os partos domiciliares é, inclusive, uma das diretrizes do movimento de desospitalização e pelo cuidado domiciliar, e podem indicar uma transição do modelo humanista para o holístico (RATTNER; AMORIM; KATZ, 2013).

Se o modelo tecnocrático é o paradigma hegemônico nas sociedades ocidentais, a abordagem holística de nascimento é quase uma heresia. Porém, dos três modelos, este é o que inclui, segundo Davis-Floyd (2001), a mais rica variedade de abordagens, indo desde uma terapia nutricional a diferentes tratamentos em Medicina complementar e alternativa, caso da Medicina Tradicional Chinesa. Insistindo na unidade de corpo, mente e espírito, o paradigma holístico vai além da definição de corpo como um organismo, definindo-o como um campo de energia em constante interaçáo com outros campos energéticos, posição conceitual que lhe possibilita adotar uma multiplicidade de abordagens hoje consideradas inaceitáveis pela Biomedicina. O modelo holístico se pauta pela individualização do cuidado e incorpora, além do entendimento do parto como evento biológico, social, cultural e sexual, o enfoque do nascimento e do parto como eventos da vida espiritual.

\section{A realidade brasileira}

No Brasil, as cesarianas seguem em ascensão, com os maiores índices encontrados no setor privado. Embora na maioria dessas instituiçóes, as taxas variem de $70 \%$ a $90 \%$, alguns hospitais particulares apresentam percentuais muito próximos dos $100 \%$. No setor público, os percentuais caem para cerca de $30 \%$, mas os nascimentos por via vaginal rotineiramente envolvem intervençóes desnecessárias (RATTNER, 2009).

Além disso, em hospitais públicos, o atendimento à parturiente costuma ser menos afetivo. No setor privado, a assistência tende a ser mais gentil e respeitosa; porém, as chances de se conseguir um parto normal são muito baixas (JONES, 2009; RATTNER; AMORIM; KATZ, 2013). O cenário brasileiro, portanto, é caracterizado pelos contrastes e torna-se uma arte (in)delicada conseguir dar à luz com dignidade e em respeito às escolhas pessoais, seja em que segmento for.

Diniz (2009) reafirma que a adoçấo da "cesárea de rotina", no setor privado, e do parto vaginal com intervençóes rotineiras, no setor público, desconsidera as evidências científicas e as reais necessidades de saúde da população. Destaca ainda que, no Brasil, convive-se com o pior dos dois mundos quanto à atenção ao parto: adoecimento e morte por falta de atenção básica e tecnologia apropriada, e adoecimento e morte por excesso de tecnologia inapropriada.

Além do contraste entre setor público e privado, o Brasil também conta com extremos geográficos quando o tema é a assistência obstétrica. Como resultado, tanto o modelo tecnocrático como o modelo mais tradicional humanista coexistem, com o primeiro prevalecendo nas Regiôes Sudeste, Sul e parte da Centro-Oeste, e o segundo ocorrendo mais nas Regióes Norte e Nordeste, onde há locais em que as parteiras tradicionais atendem quase $100 \%$ dos nascimentos; note-se que tal fato ocorre não por opção, mas por falta de condiçôes financeiras para deslocamento e internação hospitalar. Entretanto, intervençóes desnecessárias, comuns ao modelo tecnocrático, costumam ocorrer em todo o país (RATTNER; AMORIM; KATZ, 2013).

Em razão desse cenário, as mulheres brasileiras inevitavelmente têm sido alvo da chamada violência obstétrica, cujo conceito internacional define qualquer ato - ou intervenção - direcionado à mulher grávida, parturiente ou puérpera (que deu à luz recentemente), ou ao seu bebê, praticado sem o consentimento explícito e informado da mulher e/ou em desrespeito à sua autonomia, integridade 
física e mental, e aos seus sentimentos, opçôes e preferências (D'GREGORIO, 2010).

Um dos casos mais recentes e polêmicos de uma forma grave de violência obstétrica foi o de Adelir Carmen Lemos de Góes, amplamente debatido nas redes sociais (FACEBOOK, 2014) e divulgado na imprensa (MENDES, 2014; FOLHA..., 2014), com repercussão nacional e internacional, e mobilização nas ruas. Numa medida extrema, a Justiça do Rio Grande do Sul determinou que a gestante fosse submetida a uma cesariana contra sua vontade, por considerar que ela e o bebê corriam risco iminente de morte, em razão de (suposto) pós-datismo, posição fetal pélvica e duas cesáreas prévias, fatores de risco que, segundo Medicina baseada em evidência, não configuram indicação absoluta do procedimento cirúrgico (AMERICAN..., 2010).

Produzido como ausência, ou seja, como uma alternativa não credível ao que existe (SANTOS, 2002), o direito da mulher sobre o seu próprio parto é uma das principais bandeiras de um movimento feminino que cresce a cada dia no Brasil, principalmente através das redes sociais. Embrenhamo-nos virtualmente no Movimento de Humanizaçáo do Parto para conhecer como as blogueiras ativistas estão se valendo das ferramentas da internet para chamar atençáo para o problema da violência obstétrica.

\section{Violência obstétrica: ativismo virtual}

$\mathrm{Na}$ perspectiva de desvelar como ocorre essa mobilização nas redes sociais, foi empreendida viagem virtual pela blogosfera brasileira, a partir de análise qualitativa do blog Cientista que virou mãe (CQVM) (CIENTISTA..., 2011), escolhido como focus de análise por ter se consolidado como espaço de grande visibilidade e credibilidade junto ao Movimento de Humanizaçáo do Parto (MHP), tendo sido contemplado com o segundo lugar no prêmio TopBlog 2012 (TOPBLOG, 2014)를 na categoria Variedades/Júri Popular, e tendo alcançado quase um milhão de acessos (SENA, 2013b), destacando-se, assim, entre os demais previamente selecionados a partir de critérios, como popularidade, pertinência, relevância e periodicidade de atualizaçóes.

A título de informação, a lista inicial foi composta pelos seguintes blogs: Estuda, Melania, Estuda! (ESTUDA..., 2014), Parto do Princípio (PARTO..., 2014b),Mamíferas (MAMÍFERAS, 2014), Mulheres Empoderadas (LEAL, 2013), Parteria Urbana (PARTEIRA..., 2014), Parto no
Brasil (PARTO..., 2014c), Bibliografia da Doula (BIBLIOGRAFIA..., 2014) e Parto Alegre (PARTO..., 2014a). Cabe salientar, entretanto, que existem inúmeros outros blogs relevantes mantidos por ativistas, bem como diferentes espaços virtuais de informação e mobilização social para a humanização do parto, como a Rede pela Humanização do Parto e Nascimento - REHUNA (REDE..., 2014b) e a Rede HumanizaSUS (REDE..., 2014a).

A autora do blog CQVM, a paulista Ligia Moreiras Sena, é bióloga formada pela Universidade Estadual Paulista (Unesp), Mestre em Psicobiologia pela Universidade de São Paulo (USP), Doutora em Farmacologia (área de Neurofarmacologia) pela Universidade Federal de Santa Catarina (UFSC), com Pós-Doutorado também em Farmacologia, que abandonou após seis meses, para mudar de carreira. Vive em Florianópolis desde 2005, onde, na condição de Doutoranda em Saúde Coletiva na UFSC, estuda aquela que considera uma das formas mais simbólicas, opressoras e cruéis de violência: a violência obstétrica institucional, aquela que é cometida contra a mulher no momento do nascimento dos filhos.

A primeira aproximação formal ao referido $b \log$, locus de pesquisa, deu-se pela leitura de todas as postagens publicadas desde o momento de lançamento do espaço, em 26 de maio de 2009, quando o mesmo ainda era intitulado Intensa, a Mente, até 31 de dezembro de 2013, perfazendo quatro anos e sete meses de publicaçóes, somando um total de quase 450 postagens. Destas, foram selecionadas as 131 postagens que se relacionavam à temática do renascimento do parto, ou humanizaçáo do parto, para compor o corpus. Para a análise qualitativa dos dados, procedeu-se a uma leitura minuciosa dos textos, a partir da qual puderam ser elaboradas fichas catalográficas individuais, em planilhas do programa Excel.

As referidas fichas foram lidas, inicialmente em ordem cronológica inversa, conhecendo-se, assim: 1) primeiro, o desfecho e o desenrolar, e após, a semeadura das açôes pela humanização do parto; e 2) primeiro a ativista e o processo que a transformou, e depois, o embrião dessa mudança. Num segundo momento, a leitura percorreu caminho inverso, começando pela postagem mais antiga até alcançar a mais atual, a qual foi seguida, mais uma vez, pela leitura da ordem cronológica inversa. Foi esse processo de ida e vinda que possibilitou uma melhor contextualização dos fatos e uma melhor percepção da relevância dos dados na análise sobre a violência obstétrica. 
Retomando, esta engloba a violência física, moral e emocional que profissionais de saúde exercem contra a mulher que vai dar à luz, seja durante a gestaçáo, durante o trabalho de parto, no próprio parto ou ainda no pós-parto, incluindo xingamentos, humilhaçôes, piadas de mau gosto, escárnio, ironias e, também, procedimentos dolorosos, exposição física, contenção, impedimento de ser acompanhada por alguém, entre outras questóes.

Porém, como bem adverte a blogueira em tela, ainda há muitas dúvidas em relação ao conceito, inclusive entre algumas mulheres que sofreram suas consequências e não a viram como um problema, mas como sendo naturais. Trata-se, portanto, de uma violência (física e simbólica) que muitas vezes também ocorre sob o disfarce de normalidade, podendo ser atribuída, na opiniáo da blogueira, à grande parte das mulheres que adentram as instituiçóes de saúde para dar à luz e acabam vivenciando procedimentos de rotina, que, em realidade, não deveriam ser rotina (ORGANIZAÇÃO..., 1996; RATTNER; AMORIM; KATZ, 2013; DAVIS-FLOYD et al., 2009; ODENT, 2005a, 2005b; BRASIL, 2011).

[...] existem formas de violência que vão além da força e que podem ser ainda mais agressivas ou opressoras. São formas sutis e simbólicas, que se escondem no interior das instituiçóes. Muitas vezes, por serem tấo comuns e frequentes, não são vistas como violência, são vistas como ROTINA (SENA, 2012a, s/p).

O ponto de partida para o envolvimento da blogueira em tela com o tema foi a divulgação dos resultados da pesquisa Mulheres Brasileiras e Gênero nos Espaços Público e Privado (FUNDAÇÃO..., 2010), que percorreu 170 municípios brasileiros para conhecer a evolução do pensamento e do papel das mulheres no país: uma em cada quatro mulheres $(25 \%)$ relata ter sofrido algum tipo de violência na hora do parto.

Divulgados pela grande imprensa (FOLHA..., 2011), os achados da pesquisa chocam Ligia Moreiras Sena, despertando seu interesse pela violência institucional na assistência obstétrica, tanto como ativista quanto como acadêmica, dando-lhe coragem para abandonar sua carreira de Doutora em Farmacologia, com um Pós-Doutorado em andamento, para ingressar no Doutorado do Departamento de Saúde Pública da Universidade Federal de Santa Catarina (UFSC), para pesquisar a temática.

Conforme relata a blogueira, ao tomar conhecimento dos resultados da pesquisa, os coletivos femininos começam a se mobilizar em termos de circulação de informação, denúncia da situação da assistência obstétrica brasileira, reivindicação de direitos e discussão sobre o assunto. " $\mathrm{E}$ as mídias sociais apareceram como fator catalisador crucial para todas as ações que se seguiram[...]" (SENA, 2012b).

Em 25 de novembro de 2011, Dia Internacional de Combate à Violência Contra a Mulher, realiza-se a primeira blogagem coletiva, intitulada Violência Obstétrica é Violência Contra a Mulher, quando dezenas de blogueiras publicam, cada qual em seu espaço virtual, textos autorais livres sobre a questão. Nesse dia, na condição de acadêmica, Ligia lança nas mídias sociais o convite à participação em sua Pesquisa de Doutorado sobre a violência obstétrica na percepção das mulheres que a viveram. Ao explicar seu interesse e a relevância do tema, e solicitar ajuda do coletivo na divulgação da sua pesquisa, Ligia atinge centenas de mulheres que se inscrevem para serem entrevistadas.

Essa pesquisa surgiu da minha indignação. E de conseguir me colocar no lugar dessas mulheres. De compreender que sofreram, que foram negligenciadas. E de ter a convicção de que elas precisam ser ouvidas. Há muito mais violência e desrespeito nas instituiçóes de saúde, sendo cometidos contra mulheres, do que se pode imaginar. [...] Se você se sentiu desrespeitada, de alguma maneira, em seu parto e quiser dar o seu depoimento, participe desta pesquisa. [...] Há outras formas de você ajudar [...] Se você tem um blog, site, perfil no Facebook [...] me ajude a divulgar. Quanto mais mulheres participarem, mais saberemos sobre a qualidade do atendimento que as mulheres têm recebido em seus partos (SENA, 2011, s/p).

A segunda ação de ciberativismo coletivo, a pesquisa informal Teste da Violência Obstétrica, é lançada no Dia Internacional da Mulher, em 8 de Março de 2012, pelos blogsCientista que virou mãe, Parto no Brasil e Mamíferas. Divulgada por outros 74 blogs, a iniciativa tem como objetivo levantar dados sobre o tema, problematizar a questáo e levar os resultados a uma instância que ajude a incluir, nos serviços oficiais de denúncia, a violência obstétrica como forma de violência contra a mulher.

Em pouco mais de 40 dias, 1.966 mulheres respondem ao teste. Os resultados mostram que mais de $31 \%$ das mulheres sentiram-se frustradas por não terem tido o parto como haviam sonhado e que quase $17 \%$ delas sentiram raiva logo após o nascimento dos seus bebês por terem sido mal atendidas. São dados que apontam que centenas de mulheres tiveram a alegria do parto roubada pela equipe de saúde: 
[...] quase a metade das mulheres relataram terem sido vítimas de uma forma de violência; menos da metade se sentiu segura durante seu parto; 356 mulheres se sentiram ameaçadas pela equipe de saúde; 466 tiveram seu períneo cortado; 420 não puderam se movimentar, mesmo querendo; o médico ou o enfermeiro subiu em cima da barriga de 382 mulheres, para empurrar o bebê para baixo; e 1.029 mulheres não puderam segurar seus filhos no colo depois do nascimento [...] (SENA, 2012a, s/p).

Em outubro daquele ano, uma postagem coletiva dos blogsCientista que virou mãe e Parto no Brasil convida as mulheres a gravar e enviar vídeos caseiros com seus depoimentos sobre violência obstétrica, para que o vídeo documentário Violência obstétrica: a voz das brasileiras (YOUTUBE, 2012) possa ser produzido, contando com o esforço de divulgação de 70 blogs.

Lançado em 17 de novembro de 2012, como parte das comunicaçóes científicas coordenadas do Congresso Brasileiro de Saúde Coletiva, realizado em Porto Alegre, o vídeo documentário é disponibilizado para ser divulgado e compartilhado nas mídias sociais em 25 de novembro de 2012 - quando se celebra o Dia Internacional de Combate à Violência Contra a Mulher e se completa um ano de ativismo coletivo contra a violência obstétrica -, alcançando grande repercussáo.

$\mathrm{Na}$ tarde de domingo, com 12 horas de divulgação, contabilizamos cerca de 600 visualizaçóes na página do vídeo no Youtube. Na manhã do dia seguinte, ultrapassou as 9.000 visualizaçóes. Na terça-feira, com mais de 12 mil, tornou-se o terceiro vídeo mais popular na categoria "Sem fins lucrativos/ Ativismo" do Youtube - o que nos deixou pasmas [...] (SENA, 2012c, s/p).

Finalmente, em 25 de novembro de 2013, Ligia abre espaço em seu blog para divulgar uma iniciativa cujo objetivo também é dar voz às mulheres que passaram por violência obstétrica. Trata-se do documentário $A$ dor além do parto (YOUTUBE, 2013), produzido por Letícia Campos Guedes, Amanda Rizério, Nathália Machado Couto e Raísa Cruz, como Trabalho de Conclusão de Curso da Universidade Católica de Brasília, disponibilizando o link para o mesmo.

\section{Considerações finais}

Nesta investigação, confirmam-se resultados anteriores sobre como meios alternativos de comunicação e informação, como blogs e redes sociais, vêm se constituindo em formas de resistência ao pensamento único neoliberal (LUZ, 2010, 2014; LUZ; MORIGI, 2011), sendo utilizados como canais de organização coletiva contra o sistema de poder estabelecido e de contestação contra a produçáo de invisibilidades. As redes sociais vêm se consolidando como uma das principais linhas de atuação dos grupos do lado de lá da linha abissal (CASTELLS, 2013; SANTOS, 2007).

No caso específico da violência obstétrica, essas redes sociais têm permitido uma mobilização inédita em prol do respeito aos direitos reprodutivos das mulheres no Brasil. Ainda incipientes no país, as discussóes sobre o tema estão sendo alavancadas pelo uso de estratégias de ciberativismo coletivo, ao dar voz efetiva às brasileiras que passaram por situaçóes de violência obstétrica, tornando tais violências mais conhecidas, discutidas e evidentes. Desnaturalizando-as, dessa maneira.

Agindo coletivamente, as ativistas pela humanização do parto formam uma esfera pública única, mais visível e com mais probabilidade de desafiar o discurso dominante. Nesse sentido, destacam-se, em específico: as postagens coletivas, textos autorais publicados nos espaços pessoais em data pré-determinada, geralmente celebrativa, para alcançar uma maior mobilização em torno do assunto; o compartilhamento fácil e virtualmente sem custo de informaçóes, o que pode possibilitar uma disseminação de conteúdos de longo alcance e instantânea, e os canais para troca de mensagens entre pessoas ou grupos, possibilitando a fácil articulação e a organização de mobilizaçóes.

Com o Teste da Violência Obstétrica, por exemplo, as blogueiras alcançam expressiva participação de quase duas mil mulheres, conseguindo dar grande visibilidade à temática nas redes sociais e atingindo as mídias tradicionais (NORDI, 2012). Aproveitando a repercussão, disponibilizam, em conjunto com a divulgação dos resultados, cartilhas, capítulos de livros e folders, com o intuito de divulgar as estratégias e os métodos cientificamente comprovados para a proteção e a segurança das mulheres na assistência obstétrica.

Cabe salientar que a mobilização surgida nas redes sociais deixa a blogosfera para adentrar também no universo acadêmico, quando da apresentação dos resultados do Teste da Violência Obstétrica e do lançamento do documentário Violência obstétrica: a voz das brasileiras no mais importante encontro nacional em Saúde Coletiva, o 10. Congresso Brasileiro de Saúde Coletiva, realizado em Porto Alegre, em novembro de 2012. 
Dessa forma, pode-se afirmar, portanto, que os blogs podem se configurar em canais com grande potencial contra-hegemônico para o renascimento do parto e a desnaturalização da violência obstétrica, na medida em que suas autoras estão organizadas e estão se organizando para buscar uma assistência ao parto mais humanizada e menos violenta, dando maior visibilidade à temática, ao tirá-la da obscuridade.

\section{Referências}

AMERICAN COLLEGE OF OBSTETRICIANS AND GYNECOLGISTS. Practice bulletin n. 115: Vaginal birth after previous cesarean delivery. Washington: ACOG, 2010. Disponível em:<http://www.acog.org/ Resources-And-Publications/Practice-Bulletins/Committee-on-Practice-Bulletins-Obstetrics/Vaginal-Birth-After-Previous-Cesarean-Delivery >. Acesso em: 06 abr. 2014.

ARRUDA, A. Um atendimento ao parto para fazer ser e nascer. In: BRASIL. Ministério da Saúde. Relatório do Encontro Nacional da Campanha Saúde da Mulher: um direito a ser conquistado. Brasília: Ministério da Saúde, 1989. p. 335-342.

BIBLIOGRAFIA DA DOULA. Disponível em: $<\mathrm{ht}-$ tps://bibliografiadadoula.wordpress.com/>. Acesso em: 23 mar. 2014.

BRASIL. Ministério da Saúde. Portaria no 1.459 , de 24 de junho de 2011. Institui, no âmbito do Sistema Único de Saúde - SUS - a Rede Cegonha. Diário Oficial [da] República Federativa do Brasil, Brasília, DF, 24 jun. 2011. Disponível em: <http://bvsms.saude.gov.br/ bvs/saudelegis/gm/2011/prt1459_24_06_2011.html>. Acesso em: 21 mar. 2014.

BRASIL. Portaria no 904, de 29 de maio de 2013. Estabelece diretrizes para implantação e habilitação de Centro de Parto Normal (CPN), no âmbito do Sistema Único de Saúde (SUS), para o atendimento à mulher e ao recém-nascido no momento do parto e do nascimento, em conformidade com o Componente PARTO E NASCIMENTO da Rede Cegonha, e dispóe sobre os respectivos incentivos financeiros de investimento, custeio e custeio mensal. Diário Oficial [da] República Federativa do Brasil, Brasília, DF, 29 maio 2013. Disponível em: <http://bvsms.saude.gov.br/bvs/saudelegis/gm/2013/ prt0904_29_05_2013.html>. Acesso em: 21 mar. 2014.

CASTELLS, M. Redes de indignação e esperança: movimentos sociais na era da internet. Rio de Janeiro: Zahar, 2013.

CIENTISTA QUE VIROU MĀE. Florianópolis, 2011. Disponível em: <http://www.cientistaqueviroumae.com. br>. Acesso em: 22 mar. 2014.

D'GREGORIO, R. P. Obstetric violence: a new legal term introduced in Venezuela. International Journal of Gynaecology and Obstetrics, Chicago, v. 111, n. 3, p. 201-202, 2010. http://dx.doi.org/10.1016/j. ijgo.2010.09.002. PMid:20926074.
DAVIS-FLOYD, R. E. Birth as an american rite of passage. Berkeley: University of California Press, 1992.

DAVIS-FLOYD, R. The technocratic, humanistic, and holistic paradigms of childbirth. International Journal of Gynaecology and Obstetrics, Chicago, v. 75, n. 1, p. S5-S23, 2001. http://dx.doi.org/10.1016/S00207292(01)00510-0. PMid:11742639.

DAVIS-FLOYD, R. E. et al. Birth models that work. Berkeley: University of California Press, 2009.

DE VRIES, R. et al. The dutch obstetrical system vanguard of the future in maternity care. In: DAVIS-FLOYD, R. E. et al. Birth models that work. Berkeley: University of California Press, 2009. p. 31-53.

DINIZ, S. G. Gênero, saúde materna e o paradoxo perinatal. Revista Brasileira de Crescimento e Desenvolvimento Humano, São Paulo, v. 19, n. 2, p. 313-326, 2009.

DUTRA, I. L.; MEYER, D. E. Parto natural, normal e humanizado: termos polissêmicos. Revista Gaúcha de Enfermagem, Porto Alegre, v. 28, n. 2, p. 215-222, 2007.

ESTUDA, MELANIA, ESTUDA! Disponível em: $<$ http://estudamelania.blogspot.com.br/>. Acesso em: 23 mar. 2014.

FACEBOOK. Não me obriguem a uma cesárea. Disponível em: <https://www.facebook.com/naomeobriguemaumacesarea>. Acesso em: 22 mar. 2014.

FOLHA DE S. PAULO. Uma em cada quatro mulheres relata maus-tratos durante o parto. São Paulo: Folha de S. Paulo, 2011. Disponível em: <http://www1.folha.uol. com.br/cotidiano/2011/02/880316-uma-em-quatro-mulheres-relata-maus-tratos-durante-o-parto.shtml>. Acesso em: 23 mar. 2014.

FOLHA DE S. PAULO. Justiça do RS manda grávida fazer cesariana contra sua vontade. São Paulo: Folha de S. Paulo, 2014. Disponível em: <http://wwwl.folha. uol.com.br/cotidiano/2014/04/1434570-justica-do-rs-manda-gravida-fazer-cesariana-contra-sua-vontade. shtml>. Acesso em: 22 mar. 2014.

FUNDAÇÃO PERSEU ABRAMO. Pesquisa mulheres brasileiras e gênero nos espaços públicos e privados. São Paulo: FPA, 2010. Disponível em: <http://www.fpabramo. org.br/o-que-fazemos/pesquisas-de-opiniao-publica/ pesquisas-realizadas/pesquisa-mulheres-brasileiras-nos-es>. Acesso em: 25 jan. 2013.

HOGA, L. A. K. Estágio em uma casa de parto do Japão: relato de experiência. Interface: Comunicação, Saúde, Educação, Botucatu, v. 9, n. 18, p. 611-620, 2005. http:// dx.doi.org/10.1590/S1414-32832005000300015.

JONES, R. H. Team work: an obstetrician, a midwife, and a Doula in Brazil. In: DAVIS-FLOYD, R. E. et al. Birth models that work. Berkeley: University of California Press, 2009. p. 271- 304.

LEAL, G. Mulheres empoderadas. Vila Mamífera, 2013. Disponível em: <http://vilamamifera.com/mulheresempoderadas/>. Acesso em: 23 mar. 2014. 
LUZ, L. H. Ciberespaço cubano: uma forma de resistência ao poder e á censura. Revista Galáxia, São Paulo, v. 10, n. 20, p. 188-196, 2010.

LUZ, L. H. O renascimento do parto e a reinvenção da emancipação social na blogosfera brasileira: contra o desperdício das experiências. 2014. 155 f. Tese (Doutorado em Ciências Sociais) - Universidade Federal do Rio Grande do Norte, Natal, 2014.

LUZ, L.; MORIGI, V. J. O ciberespaço e a reconfiguração da esfera pública: os blogs cubanos como prática de cidadania. In: MORIGI, V. J.; TOURINHO, I. M.; ALMEIDA, C. D. Comunicação, informação e cidadania: refletindo práticas e contextos. Porto Alegre: Sulina, 2011. p. 193-201.

MAMÍFERAS. Disponível em: <http://vilamamifera. com/mamiferas/>. Acesso em: 23 mar. 2014.

MENDES, V. Justiça retira mãe em trabalho de parto de casa para obrigá-la a fazer uma cesariana. Belo Horizonte: Saúde Plena, 2014. Disponível em: <http://sites.uai. com.br/app/noticia/saudeplena/noticias/2014/04/02/ noticia_saudeplena, $148157 / \mathrm{mandado}$-judicial-retira-mae-em-trabalho-de-parto-de-casa-para-obriga.shtml>. Acesso em: 22 mar. 2014.

NAGAHAMA, E. E. I.; SANTIAGO, S. M. A institucionalização médica do parto no Brasil. Ciencia \& Saúde Coletiva, Rio de Janeiro, v. 10, n. 3, p. 651-657, 2005. http://dx.doi.org/10.1590/S141381232005000300021 .

NORDI, D. Pesquisa mostra violência contra mulher durante o parto. São Paulo: Portal iG Delas, 2012. Disponível em: <http://delas.ig.com.br/filhos/2012-06-04/ pesquisa-mostra-violencia-contra-mulher-durante-o-parto.html>. Acesso em: 23 mar. 2014.

ODENT, M. A cientificação do amor. Florianópolis: Saint Germain, 2002.

ODENT, M. A cesariana: operação de salvamento ou indústria do nascimento? Lisboa: Miosótis, 2005a.

ODENT, M. O renascimento do parto. Florianópolis: Saint Germain, 2005b.

ORGANIZAÇÃO MUNDIAL DA SAÚDE - OMS. Assistência ao parto normal: um guia prático. Genebra: OMS, 1996.

PARTERIA URBANA. Disponível em: < vilamamifera. com/parteriaurbana/>. Acesso em 22 mar.2014.

PARTO ALEGRE. Disponível em: <https://partoalegre. wordpress.com/>. Acesso em: 23 mar. 2014a.

PARTO DO PRINCÍPIO. Disponível em: <http://partodoprincipio.blogspot.com.br/>. Acesso em: 23 mar. $2014 b$.

PARTO NO BRASIL. Disponível em: <http://www. partonobrasil.com.br/>. Acesso em: 23 mar. 2014c.

RATTNER, D. Humanização na atenção a nascimentos e partos: breve referencial teórico. Interface: Comunicação, Saúde, Educação, Botucatu, v. 13, n. 1, p. 595-602, 2009. http://dx.doi.org/10.1590/S141432832009000500011 .

RATTNER, D.; AMORIM, M.; KATZ, L. Implementação da humanização na atenção a partos e nascimentos pelo Ministério da Saúde. In: URBANETZ, A. A.; LUZ, S. H. Programa de Atualização em Ginecologia e Obstetricia - PROAGO. Porto Alegre: Artmed/Pan-americana, 2013. p. 95-145.

REDE HumanizaSUS. Disponível em: <http://www.redehumanizasus.net/>. Acesso em: 23 mar. 2014a.

REDE pela Humanização do Parto e Nascimento REHUNA. Disponível em: <http://www.rehuna.org. br/>. Acesso em: 23 mar. 2014b.

SANTOS, B. S. Para uma sociologia das ausências e uma sociologia das emergências. Revista Crítica de Ciências Sociais, Coimbra, v. 63, p. 237-280, 2002.

SANTOS, B. S. Para além do pensamento abissal: das linhas globais a uma ecologia de saberes. Revista Critica de Ciências Sociais, Coimbra, v. 78, p. 3-46, 2007.

SENA, L. M. Desrespeito e violência no parto - convite à pesquisa. Florianópolis: Cientista que virou Mãe, 2011. Disponível em: <http://www.cientistaqueviroumae.com. br/2011/11/desrespeito-e-violencia-no-parto.html>. Acesso em: 23 mar. 2014

SENA, L. M. Entrevista para Rádio CBN e participação no Mamatraca. Florianópolis: Cientista que virou Mãe, 2012a. Disponível em: <http://www.cientistaqueviroumae.com.br/2012/06/entrevista-para-radio-cbn-e. html>. Acesso em: 23 mar. 2014.

SENA, L. M. Violência obstétrica: a voz das brasileiras: assista! Florianópolis: Cientista que virou Mãe, 2012b. Disponível em: <http://www.cientistaqueviroumae.com. br/2012/11/violencia-obstetrica-voz-das_25.html>. Acesso em: 23 mar. 2014

SENA, L. M. A repercussão do documentário. Florianópolis: Cientista que virou Mãe, 2012c. Disponível em: <http://www.cientistaqueviroumae.com.br/2012/11/a-repercussao-do-documentario.html>. Acesso em: 23 mar. 2014.

SENA, L. M. Quase um milhão de motivos para agradecer: novo layout do Cientista Que Virou Mãe. Florianópolis: Cientista que virou Mãe, 2013b. Disponível em: <http:// www.cientistaqueviroumae.com.br/2013/07/um-milhao-de-motivos-para-agradecer.html>. Acesso em: 22 mar. 2014.

TOPBLOG. Disponível em: <https://topblogbrasil.wordpress.com/sobre/>. Acesso em: 22 mar. 2014.

YOUTUBE. Violência obstétrica - a voz das brasileiras. 2012. Disponível em: <https://www.youtube.com/watc $\mathrm{h}$ ? $\mathrm{v}=\mathrm{eg} 0$ uvonF25M\&feature $=\mathrm{kp}>$. Acesso em: 23 mar. 2014.

YOUTUBE. A dor além do parto. 2013. Disponível em: <https://www.youtube.com/watch?v=cIrIgx3TPWs >. Acesso em: 23 mar. 2014. 


\section{Contribuição dos autores}

Lia Luz foi responsável pelo trabalho de concepção do texto e análise dos blogs. Vânia de Vasconcelos Gico foi responsável pela supervisão, orientação do trabalho, revisão final do texto e dos resultados da pesquisa. As autoras aprovaram a versão final do texto.

\section{Fonte de financiamento}

\section{CAPES- DS}

\section{Notas}

${ }^{1}$ O Prêmio TopBlog é um sistema de incentivo cultural destinado a reconhecer e premiar, mediante votação popular e acadêmica, os blogs brasileiros mais populares, que possuam a maior parte de seu conteúdo focado para o público brasileiro, com melhor apresentação técnica. 